\title{
GPS 在摄影测量与遥感中应用的现状与趋势
}

\author{
李海博 \\ 阜新市规划设计研究院有限公司 \\ DOI:10.32629/gmsm.v2i2.105
}

[摘 要] 随着科技水平的不断提升,GPS 技术凭借自身具有的优势特点, 在我国各大领域的应用越来越广泛, 不仅对国家的军 事、科研、导航做出了突出贡献,并日渐扩展到各类工程建设中,对众多行业发展起到了促进作用。特别是在摄影测量中,GPS 的定位技术以其操作简便,精准度高, 全天候, 速度快、费用省、不受通视条件限制等优良特性被广泛应用,下面我们主要来谈谈 GPS 在摄影测量与遥感中应用的有关问题。

[关键词] GPS；摄影测量；定位；技术

\section{GPS 技术概念}

GPS 是全球定位系统的英文简称, 主要借助卫星定位导 航系统, 实现全方位的定位观测。GPS 技术具有较多的优势 特点: 第一, 受自然环境影响小, 当前 GPS 只有在重大雷雨天 气不适合进行观测。第二, 观测时间短。根据观测类型不 同, GPS 的观测时间有所差异, 但是较其他技术而言, 该技术 观测时间较短, 其中动态定位仅需几秒钟。第三, 定位精度 高。GPS 技术的定位精准度已经达到厘米级, 其中 GPS-RTK 精度实现了 1-2 厘米, GPS-RTD 精度达分米级。第四, 操作简 单。GPS 具有较高自动化水平, 在进行定位观测时, 操作人员 只需完成仪器的安置工作。

\section{GPS 摄影测量的原理}

GPS 主要是向太空中几十颗卫星不断发射导航信号, 用 户通过 GPS 终端对以上信号进行接收, 并且将自身所在地理 位置的详细数据进行精准确定的系统。在 GPS 的作用下, 人 们能够在世界任何信号好的地理位置对自身所处的经纬度、 高度数据进行整体的把握。得到了以上数据, 可以将其融汇 于照片中, 进而将拍摄地点的信息完整的保留下来。另外, 对这些数据进行更为深入的加工对路径导航的发展还有一 定的促进作用。GPS 摄影测量要获得摄影测量点的三维几何 坐标, 测量时不仅能够获得点的三维几何坐标, 其高程精度 还能得到有效保障。在摄影中三角测量是以拍摄像片所量测 的像点坐标作为原始数据, 以少量地面实测的控制点地面坐 标为基础, 在完成了以上工序后, 得到了比较可信的数据, 然 后运用科学的计算方法得到了加密点的地面坐标, 做到了这 些, 摄影测量所需要的标准才能够达到。航测控制测量时, 要对所有布设的像控点进行整网平差, 这样才能得到可信度 比较高的三维坐标信息。

\section{3 遥感技术}

遥感技术作为一项远距离探测技术, 其主要就是能够在 不同角度、不同距离的情况下对地面物体进行探测监视, 例 如地面的房屋、山体、草地、树木以及河流海洋等。在探测 过程中可以获取到电磁波、地震波以及电场磁场等信息, 并 将这些信息提取出来进行判定, 再进行加工处理和分析, 从
而使这些数据能够在某方面工作中得到应用, 在应用过程中 充分体现了其频率快、覆盖广以及信息大等多项优势, 同时, 遥感技术在应用过程中也需要相应的技术设备和多种学科 知识的相互配合, 可见遥感技术也是一项具有较高综合性、 复杂性的探测技术。

\section{GPS 在摄影测量中的优点}

在 GPS 出现以前摄影地面控制点的测量点大部分主要 来自以往传统的经纬仪和测距仪及全站仪等摄影测量这些 常规的工具, 但这些常规仪器测量都必须满足控制点之间相 通视的原则, 不然就达不到摄影测量的要求, 很多地理位置 差点的地方往往不能完成摄影测量的工作, 由于在不同地区 “测区高程异常变化也不同”使得在我国西部地区的摄影测 量三维信息的利用问题还有待进一步试验和研究但是现在 有了 GPS 技术的加入, 摄影测量不再一定需要有控制点 了, GPS 在摄影测量中不但摄影测量精度高而且速度快, 因而 GPS 摄影测量技术很快就取代了常规摄影测量技术, 一跃成 为摄影测量的主要技术手段。

\section{GPS 在摄影测量中的具体应用}

5.1 GPS 应用于航空摄影测量

航空摄影测量作为一种新型的摄影测量技术, 实现了 航空摄影测量与 GPS 定位融合, 将两者技术优点集于一身, 是摄影测量领域的重要技术突破。所谓 GPS 航空摄影测量 技术, 就是在航摄飞机上安装相关仪器, 实现对 GPS 信号 的接受, 并利用 GPS 动态定位进行瞬间摄影的技术。GPS 在航空摄影测量中的运用, 分为如下几个步骤: 第一, 航空 摄影。航摄仪对测区进行摄影时, GPS 接收机会架设相应 的控制点, GPS 地面基准站可对地面控制点进行观测。第 二, 像控点布设。根据收集的飞行数据, 在分析与处理的基 础上进行少量像空点布设, 一般选择测区四角与中心位置, 之后对象控点目标进行联测, 均以 3 次为标准, 以 3 次的平 均值作为控制点的成果值。第三, 数据预处理。外方位元 素求解与空中三角测量是数据预处理的两个重要过程, 借 助同步的 GPS 基站, 实现对控制点数据的精准测量, 并依 据航摄时间记录以及惯性测量单元数据进行计算, 从而获 
得姿态数据。第四, 立体测图。根据以上元素数据与数字 摄影结果, 按照一定的比例生产测绘产品, 完成测区范围 内的地形图。

\subsection{GPS-RTK 技术的应用}

RTK 是更高精度的 GPS 测量技术, 中文全称为载波相 位动态实时差分技术, GPS-RTK 技术的实现主要借助 GPS 接收设备、数据传输设备、差分处理软件等, 由于其具有 的定位精度更高, 将其运用于摄影测量技术发挥的作用将 更加显著。现对 RTK 技术的优势特点加以概述：首先, 该 技术要求具有电磁波通视条件, 相应的对能见度的要求降 低, 对季节和气候等环境因素降低了要求, 进行摄影测量 时不受气候环境的影响。其次, RTK 定位精度实现了厘米 级别, 将 GPS-RTK 技术应用于摄影测量中, 可以在运动过 程中进行高精度的瞬间摄影, 对于摄影测量工作而言, 既 缩短了测量耗费的时间, 又提高了摄影测量质量。最 后, RTK 是对 GPS 技术的创新, 将其运用于摄影测量领域, 可进一步发挥 GPS 技术的实效, 极大的推进了摄影测量技 术的发展。

\section{6 基于 GPS 技术的遥感测绘}

在航空摄影测量的实际操作中, 主要是利用飞机上的航 空摄影仪器对地面进行连续取像, 并结合地面控制点测量技 术、调绘技术以及立体测绘等步骤完成地形图的绘制工作, 具体的操作步骤主要是:

6. 1 利用相关设备进行数据采集工作, 包括模型点坐标、像 点坐标以及转点等, 并根据实际情况做出相应的调整改正, 确 保采集到的数据具备完整性、准确性以及真实性。
6.2 进行数据处理工作, 通常在实际工作中都会采用区域 网平差, 这种方式主要是利用多条航空航线构成的区域进行整 体平差, 而且在平差过程中也常常需要加入非摄影类测量信息, 也就是地面控制点的坐标, 可以使得航空摄影测量网归入到规 定的坐标系之中, 在这个过程也要及时改正像片系统中的误 差。同时, 航空摄影测量的工作也分为外业和内业, 外业工作 主要是像片控制点联测、像片调绘以及综合法测图, 而外业 则是测图控制点的加密和地形图的绘制，而在 GPS 的应用 下, GPS 可以与全数字化自动摄影测量集成运用, 使得航空摄 影测量工作中的外业控制到内业加密、数字高程模型、数字 正射影像以及数字线划图的全过程更具有高效性, 极大缩短 了时间成本, 减少了资源消耗。

\section{7 结语}

总之, GPS 技术在摄影测量和遥感领域中将会有更大的 发展空间, 其频繁的应用将会引领全球环境遥感监测技术的 变革创新, 这一新型技术全球性、全能性、全天候性的导航 定位、定时、测速的优势将会最大限度的促进测绘行业的发 展, 为社会、为广大人民群众创造更大的经济利益, 为提升我 国的国民经济实力推波助澜。

\section{[参考文献]}

[1]李玲.浅谈 GPS 在摄影测量中的应用 [J].计算机光盘 软件与应用,2013,(2):36.

[2]冯秀江,孙金玲.GPS 在摄影测量中的应用[J].黑龙江 科学,2013,(9):41.

[3]马成.GPS 在摄影测量中的应用探析[J].科技创新与 应用,2015,(6):63. 